\title{
Risk assessment in the plateau pika (Ochotona curzoniae): intensity of behavioral response differs with predator species
}

\author{
Wanrong Wei ${ }^{1,2^{*}}$, Qiaoyan Zhen ${ }^{3}$, Zhongmin Tang ${ }^{4}$ and Maria K. Oosthuizen ${ }^{5,6}$
}

\begin{abstract}
Background: The ability of a prey species to assess the risk that a predator poses can have important fitness advantages for the prey species. To better understand predator-prey interactions, more species need to be observed to determine how prey behavioral responses differ in intensity when approached by different types of predators. The plateau pika (Ochotona curzoniae) is preyed upon by all predators occurring in its distribution area. Therefore, it is an ideal species to study anti-predator behavior. In this study, we investigated the intensity of anti-predator behavior of pikas in response to visual cues by using four predator species models in Maqu County on the eastern QinghaiTibetan Plateau.

Results: The behavioral response metrics, such as Flight Initiation Distance (FID), the hiding time and the percentage of vigilance were significantly different when exposed to a Tibetan fox, a wolf, a Saker falcon and a large-billed crow, respectively. Pikas showed a stronger response to Saker falcons compared to any of the other predators.

Conclusions: Our results showed that pikas alter their behavioral (such as FID, the hiding time and the vigilance) response intensity to optimally balance the benefits when exposed to different taxidermy predator species models. We conclude that pikas are able to assess their actual risk of predation and show a threat-sensitive behavioral response.
\end{abstract}

Keywords: Predator-prey interactions, Plateau pika, Anti-predator behavior, FID, The hiding time, Vigilance

\section{Background}

It is crucial for prey species to evaluate and respond adaptively to risks posed by their predators, as predators have strong direct and indirect risk effects on prey species. Prey species can be exposed to a wide range of predator species that differ in size [1], density [2], habitat use [3], diel activity [4] and hunting styles [5] in natural systems. Studying the behavioral response intensity of prey to risks posed by different predator species, is therefore

\footnotetext{
*Correspondence: weiwr18@126.com

${ }^{1}$ Key Laboratory of Southwest China Wildlife Resources Conservation, College of life Sciences, China West Normal University, Nanchong 637009, China

Full list of author information is available at the end of the article
}

an important component of improving our understanding of predator-prey interactions [6, 7].

Predation is a pervasive selection force that influences physiological, morphological, and behavioral adaptations in prey species in order to increase the chances of a successful escape [8]. Generally, the assessment of predation risk is translated into the display of an antipredator behavior. Antipredator behavioral responses to predation risks include a reduction in foraging activity $[9,10]$, increased vigilance $[11,12]$, reduced movement [13], reduced use of conspicuous behavioral displays [14], increased hiding time in a refuge or shelter $[14,15]$, and increased alarm calls $[16,17]$. However, these behavioral strategies have associated costs, as they can provoke a reduction in factors such as energy intake, energetic 
investment in defensive structures, or lower mating success. As risk assessment is difficult to quantify, most studies use Flight Initiation Distance (FID), the hiding time in a refuge and vigilance as the metrics to study the risk levels associated with antipredator behaviors of prey species [7, 14, 18-22]. FID is the distance at which a prey starts to flee upon approach of a predator [23, 24]. Prey approached by predators often flee into refuges and emerge after a brief stay $[15,25]$. The hiding time is the time from the moment that prey hides in refuge to the moment that it re-emerges again [26]. Vigilance is the time that prey spend in gathering information that is used to observe predators and assessing the potential predation risk [27]. In general, a longer FID, a longer hiding time in a refuge and higher vigilance means that the prey is experiencing a higher risk of predation $[22$, 26-33].

A growing number of studies demonstrated that prey can assess their actual risk of predation and shape their antipredator effort accordingly in response to different degrees of predation threat, which supports the threatsensitive predator avoidance hypothesis. The threat-sensitive predator avoidance hypothesis has been verified in many animals, including insects, crabs, fish, amphibians, reptiles, mammals and birds [23, 28, 34-40]. These studies have shown that prey usually exhibit different antipredator behavioral response intensities when attacked by predator species which exhibit different levels of predation risks. However, to our knowledge, this hypothesis has rarely been tested in small, burrowing, grassland herbivores in the wild.

The plateau pika (Ochotona curzoniae) is a small, diurnal, social burrowing herbivorous lagomorph, which occurs in most areas above an altitude of $3300 \mathrm{~m}$ in the Tibetan plateau [41]. The pika is an ideal species to study the assessment of predation risk because they are preyed upon by nearly all of the predators occurring on the plateau. These predators include wolves (Canis lupis), Tibetan foxes (Vulpes ferrilata), snow leopards (Uncia uncia), brown bears (Ursus arctos), steppe polecat (Mustela eversmanni), Alpine weasel (Mustela altaica pallas), golden eagles (Aquila chrysaetos), upland buzzards (Buteo hemilasius), saker falcons (Falco cherrug), goshawks (Accipiter gentilis), black kites (Milvus migrans), little owls (Athene noctua) and large-billed crows (Corvus macrorhynchos tibetosinensis) [42-44]. Previous studies demonstrated that the Tibetan fox and the Saker falcon are regarded as the most threatening predators for pikas since the Tibetan fox is a pika specialist $[45,46]$ and pikas are a main food source of the Saker falcon (90\% of pellets under the nest of a Saker falcon contained pika remains) [42]. Wolves and crows hunt pikas opportunistically or when other food is scarce, but generally do not pose a serious risk to pikas [7, 47, 48]. In addition, a previous study found that pikas responded differently when they were presented with the calls of different predators [7]. Therefore, it is believed that different types of predators represent different risk levels to pikas [7].

Encounters between predator and prey are rarely observed in nature. For this reason, the predator models have been evaluated using indirect studies [49-53]. In this study, we conducted a field experiment to test 'the threatsensitive predator avoidance hypothesis' using burrowing plateau pikas. We exposed the pikas to four of their common predators, the Tibetan fox, wolf (Canis lupis), Saker falcon and large-billed crow, representing different levels of predation risk to the pikas. We assumed that the Tibetan fox and Saker falcon are more threatening predator species than the wolf and large-billed crow based on whether pikas are the main food source for these predators. We hypothesized that the pika would have the ability to assess the level of predation risk and exert different behavior response intensities when exposed to different predator species models. Specifically, we predicted that: (1) pikas would be longer FID when exposed to a more threatening predator species model; (2) the hiding time in a refuge would be longer after an unsuccessful 'attack' by a more threatening predator species model; and (3) pikas would allocate more time to vigilance (vigilance is defined as the total duration of time that a pika has its head lifted above its back) when they re-emerge from a refuge after an unsuccessful 'attack' by a more threatening predator species model.

\section{Results}

When approached by a saker falcon, crow, fox or wolf, pikas maintained $16.8 \mathrm{~m}, 7.1 \mathrm{~m}, 8.8 \mathrm{~m}$ and $5.1 \mathrm{~m}$ in FID, respectively (Fig. 1a, b; Fig. 2). Pikas spent 898 s, 263 s, $299 \mathrm{~s}$ and $248 \mathrm{~s}$ in the refuge, respectively, following an unsuccessful predation by a saker falcon, crow, fox or wolf (Fig. 1a, b; Fig. 2). In addition, when reemerging from the refuge, pikas spent about $74 \%, 57 \%, 61 \%$ and $56 \%$ of their time during the first $10 \mathrm{~min}$ on vigilance after an unsuccessful predation by a saker falcon, crow, fox or wolf, respectively (Fig. 1a, b; Fig. 2). A mixed linear model analysis showed that SM $(F=7.492$, $p=0.001)$ and GS $(F=34.864, p<0.001)$ had significant effects for FID, while $\mathrm{P}(F=0.058, p=0.944)$ and EO $(F=0.907, p=0.533)$ had not, and the interaction effects between SM and GS was significant $(F=6.187$, $p=0.002$ ). However, for the hiding time in the refuge, Kruskal-Wallis tests showed a significant difference across different predator species model treatments $(p<0.05)$. After the $p$ was adjusted, we found no significant difference between wolf and crow ( $p=1$; Fig. 2), fox and crow ( $p=0.163$; Fig. 2$)$ and between saker 


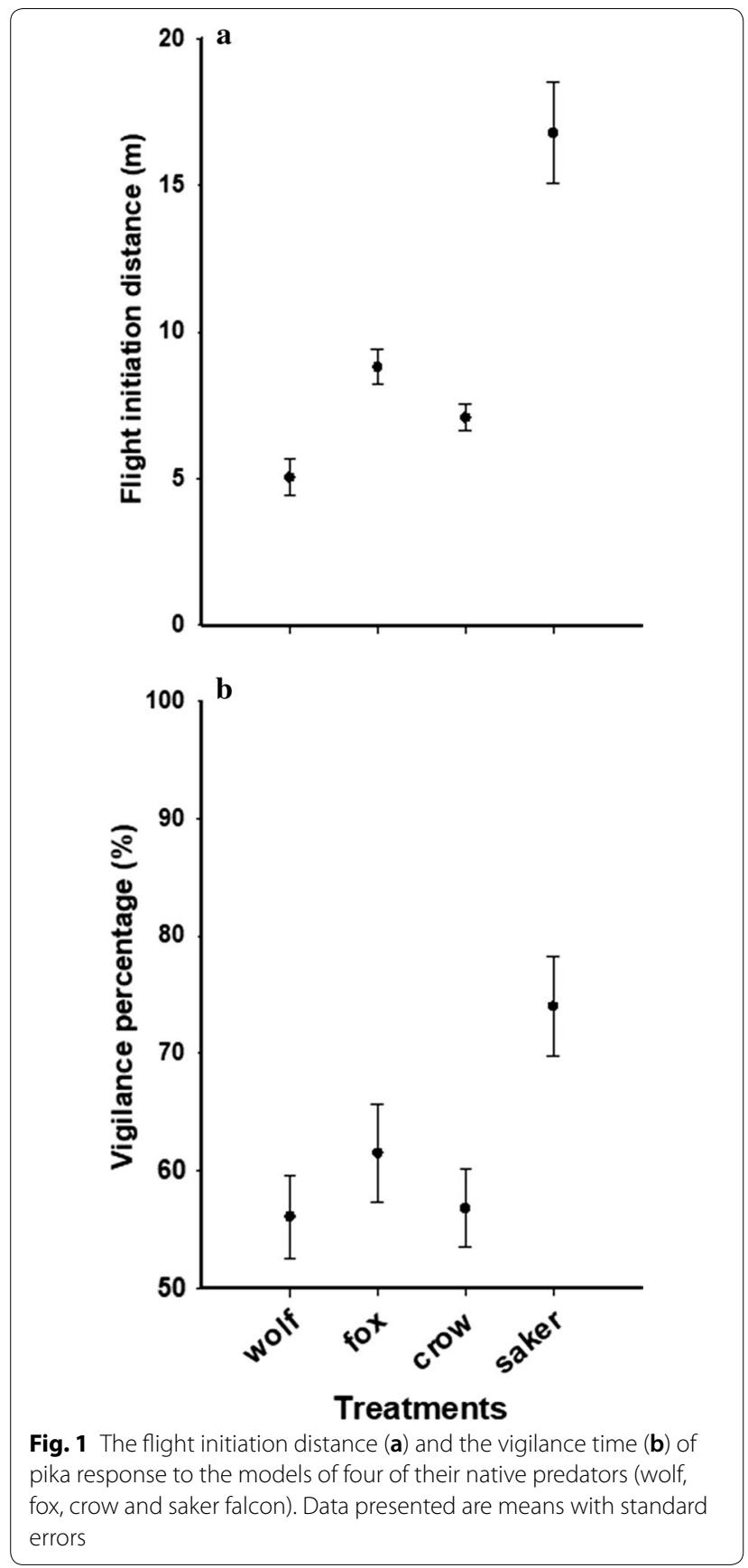

falcon and fox ( $p=0.120$; Fig. 2). However, there was a significant difference between wolf and fox $(p=0.004$; Fig. 2), between wolf and saker falcon $(p<0.001$; Fig. 2) and between crow and saker falcon $(p<0.001$; Fig. 2). A mixed linear model analysis showed that SM $(F$-value $=6.329, p=0.002)$ and GS $(F=16.684$, $p<0.001)$ had significant effects in vigilance, while $\mathrm{P}$ $(F=0.780, p=0.468)$ and EO $(F=1.288, p=0.285)$ had not. However, the interaction effects $(F=3.573$,

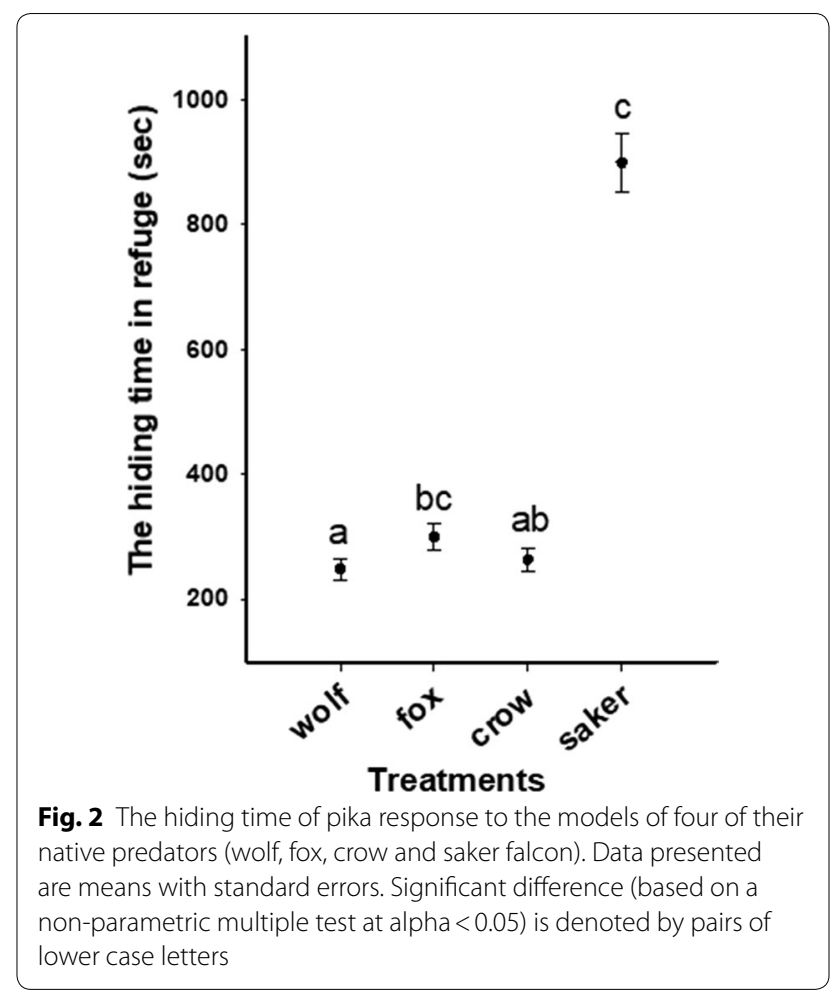

$p=0.026)$ of SM and GS did differ significantly in vigilance.

\section{Discussion}

The results from our study provide evidence that pikas display different behavioral response intensities when exposed to different predator species models. The saker falcon is perceived as the greatest threat by pikas as it elicited the strongest anti-predator behavioral response, with the longest FID and hiding time in the refuge, and the highest vigilance percentage. Our results support the 'threat-sensitive predation avoidance hypothesis' that pikas have the ability to assess the degree of risk posed by a predator, and that responses are graded in intensity depending on the threat level perceived $[49,54]$. Compared to the previously studies $[7,48]$, this is the first report to assess pika anti-predator behavior in response to the presence of different predator species. These results provide valuable information that may be used in the biological control of one species that can be inhibited by using the interrelationships with another species.

Prey minimizes the cost of escape by remaining where they are until the potential cost of staying outweighs the benefits $[19,21,55]$. This suggests that when a prey detects a predator early, it should delay escape attempts until some criterion relating to escape costs to the cost of not fleeing is met. According to the escape theory, 
predators with a higher risk are associated with greater FID [56, 57], while FID is expected to be shorter when predation risk is lower [58]. Our results showed that the FID was strongly influenced by the SM. GS is known to affect the ability of prey animals to detect predators [59], which then alter the FID [38]. We also found GS has a significant influence on FID.

Prey often respond to predator attacks by hiding in their refuges or safe microhabitats $[60,61]$. However, remaining in refuges can also incur fitness costs, and the decision of when to come out from a refuge after an unsuccessful attack by a predator is an important component of anti-predator behavior $[21,22]$. There is a tradeoff between staying in refuge with a diminishing risk of predation over time, but with the increased risk of starvation while in the refuge $[10,61,62]$. Cooper and Frederick [21] demonstrated that the hiding time in a refuge should be longer when the perceived risk is higher. Our results are similar to previous studies [24, 63, 64], and support the view that the hiding time in refuge changed with exposure to different predators which present different level of risk.

The level of vigilance is associated with predation risk and vigilance can increase the ability of prey to gather information about the current predation risk [7, 9]. In addition, the vigilance level of prey depends on the level of previous predation risk [9]. In general, prey reduced foraging time and engaged in anti-predator behavior when the previous predation risk was high [9]. Our results indicate that the vigilance level was significantly higher in response to a saker falcon compared to the other predators, which indicates pikas perceive the saker falcon as the greatest risk of our four test predator species.

Aerobic movements of animals is energetically costly, especially in QTP [41]. The reduction of unnecessary aerobic movements lowers energetic costs and can increase the survival rate of pikas [41]. Pikas have adapted to display varying anti-predator behavioural response intensities depending on the level of risk posed by different predators [7]. The results of the present study indicate that the saker falcon is regarded as the most dangerous predator because pikas elicited the strongest anti-predator response (for example, the furthest FID, the longest hiding time in refuge and the highest vigilance percentage) when exposed to it. A possible explanation for the difference in responses elicited by the different predators is the difference in the approach speed of the different predator species. Zhang et al. [7] suggested that raptors (eagle and falcon) are more threatening than beasts (fox and wolf) because raptors approach faster. In contrast, our results indicate that the threat of a fox is greater than that of a crow [7]. Thus, a more likely explanation for the difference in behavioral response intensities are related to whether the pika is the main food resource for the specific predator. In addition, our results also indicate that the saker falcon poses a greater threat to pikas than the fox, implying that pikas are able to evaluate risk levels by assessing the predator visually and having stronger antipredator behavioral responses when facing a more threatening predator. The ability to discriminate between more and less dangerous predators can have significant advantages for pika survival. Many other animals also vary their behavioral response intensity depending on the predator species [23, 28,34-40], and this adaptation is as a result of co-evolution with predators over millions of years [7]. However, it is not known whether the ability of pika to discriminate between predators is innate or based on experience and would require further studies to elucidate this.

Predators play an important role in the control of pikas as the direct and indirect predation risk effects can significantly affect the fertility and survival of pikas $[45,65]$. Over the past decades, plateau pikas have been targeted for control by poisoning primarily because they are believed to have a negative impact on rangeland and compete with livestock for food [43]. An unfortunate consequence of these poisoning campaigns to kill pikas is that the predator species may inadvertently be poisoned [43]. Besides that, many predators of pikas are being killed for profits [48]. The situation is further exasperated by the fact that the pika fertility is far greater than that of its predators [48], and the pika population can recover rapidly to its original state in a short time [66]. whereas the predator numbers remain low due to the killing and poisoning campaigns. Essentially the natural mechanism of pika population control is eliminated from the system, and the pika populations continue to increase unchecked. Therefore, it is imperative that the poisoning campaigns and the killing of carnivore campaigns should be halted.

\section{Conclusions}

Our results show that pikas are able to discriminate between predator species which present different levels of risk and alter their response according to what is likely to be a larger threat. In addition, our results also provide support to previous studies suggesting that the saker falcon is the most threatening predator of pikas in the alpine meadow of the Qinghai-Tibet Plateau. Finally, given the critically important role of predators of pikas in controlling their population densities we urge that the campaigns to poison pikas and the killing of their carnivore predators should be terminated. 


\section{Materials and methods}

\section{Study site}

The study site is located in a natural alpine meadow in Luqu County, Gansu province, northwestern China. Geographically, the study site is located on eastern part of Qinghai-Tibetan plateau (lat. $34^{\circ} 14^{\prime} \mathrm{N}$; long. $102^{\circ} 13^{\prime}$ $\mathrm{E}$; alt. $3650 \mathrm{~m}$ ). The site has a typical alpine continental climate, with mean annual temperatures of $2.3{ }^{\circ} \mathrm{C}$. The average annual precipitation is $543.6 \mathrm{~mm}$, and occurs predominantly between June and September. The main soil type is subalpine meadow soil. The vegetation type is alpine meadow, and dominant species is Kobresia humilis, Elymus nutans, Festuca ovina L, Polygonum viviparum L, Anemone obtusiloba D. The inclination of study site (plateau pika habitat) is about $13^{\circ}$ on a western slope. In this area, the distribution of pika families is patchy and each family contains 4-7 individuals. In our study area, the range of the active area of a pika family is about $470-680 \mathrm{~m}^{2}$.

\section{Experiment design}

The experiments were conducted 15-29 June, 2016, after the breeding season. We randomly selected three different pika populations (P) which were spatially nonadjacently distributed in our study site. Ten days before the start of the experiment, we placed two iron pillars (50 $\mathrm{cm}$ diameter, $3 \mathrm{~m}$ high) in each area, where one pillar was situated in the pika colony, the other was situated on the slope above the pika habitat, and the distance between the two pillars was $50 \mathrm{~m}$ (Fig. 3). The two pillars were connected by a rope that was strong enough to hold and slide the predator models. The height of the rope was adjusted depending on the predator species. We fixed an infrared high definition camera (Huian: WL1008T, LED, 2megapixel, 12.8, Progressive ScanCMOS,

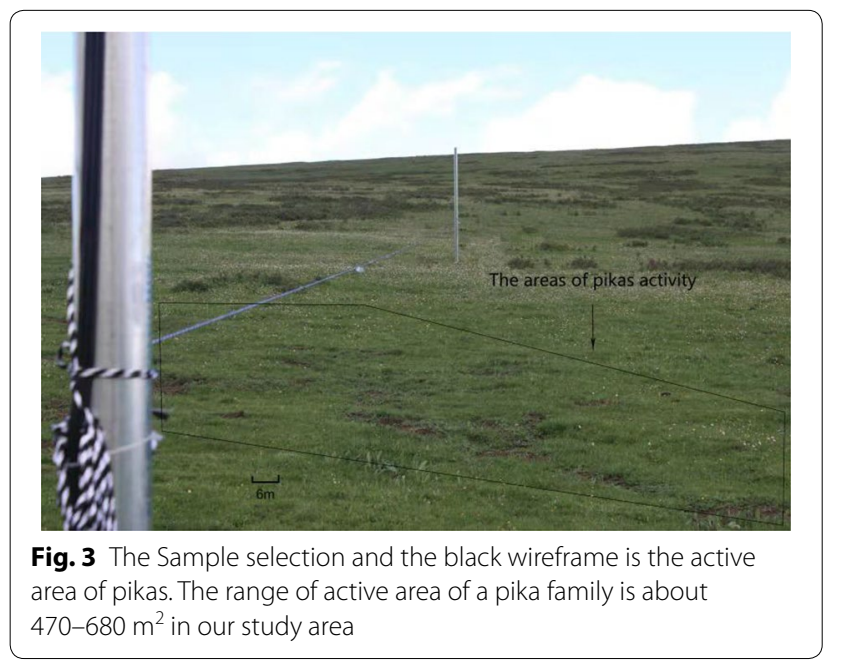

$1920 \times 1080 \mathrm{fps})$ that can rotate $360^{\circ}$ on the pillar that was in the colony, and used a cable to connect it to a computer (Lenovo, G5050) in a tent that was $400 \mathrm{~m}$ away from the pika colony. During the experiments, the anti-predator behavior of the pikas were observed and recorded. We tested four different conditions: a wolf (length: $135 \mathrm{~cm}$, width: $25 \mathrm{~cm}$, height: $30 \mathrm{~cm}$ ), a Tibetan fox (length: $50 \mathrm{~cm}$, width: $15 \mathrm{~cm}$, height: $35 \mathrm{~cm}$ ), a largebilled crow (length: $10 \mathrm{~cm}$, width: $5 \mathrm{~cm}$, height: $15 \mathrm{~cm}$ ) and a saker falcon (length: $45 \mathrm{~cm}$, width: $150 \mathrm{~cm}$, height: $25 \mathrm{~cm}$ ). The four predator models served as the predator species models (SM) (Fig. 4). Each population was tested for 4 cycles (each cycle was 2 days long) and the interval between cycles was at least 2 days. A cycle consisted of presenting each of the four predators to a colony of pikas. The order (EO) of the predators was randomized to avoid habituation of the pikas to the experimental procedure, while the interval between different predators in a cycle was at least $3 \mathrm{~h}$. In addition, we recorded the survey dates (SD) of SM in different $\mathrm{P}$.

During the experimental procedures, the predator models were placed on the rope and a person dragged the model from the upper pole to the lower pole inside the pika colony with a rope by walking $80 \mathrm{~m}$ away (Human activities affect the activity of pikas at distances closer than $30 \mathrm{~m}$ ) [66], parallel to the model at a speed of $5 \mathrm{~m} / \mathrm{s}$. When pikas hid in their burrows, the predator model was moved back up to the upper pole. Tests were conducted in the morning during peak hours of pika activity (8:009:00) on a sunny day. Taking into account the height of the animal and its hunting style, we adjusted the height to $40 \mathrm{~cm}, 90 \mathrm{~cm}, 120 \mathrm{~cm}$ and $130 \mathrm{~cm}$ for the tibetan fox, wolf, large-billed crow and Saker falcon, respectively. Trials were stopped if there were predators in the surrounding environments.

We analyzed the videos at one quarter speed and scored the hiding time and vigilance using $J$ Watcher 1.5.0. In our experiments, we only observed adult pikas whose vigilance direction was opposite to that of the approaching predator model to determine the FID because vigilance direction can influence the FID [23, 67]. In addition, group size (GS) was quantified as it can also influence FID [7]. When all experiments were analyzed, we measured the FID and the refuge distance (RD) measured for individual observed pikas, the FID and refuge distance was measured to the nearest $0.1 \mathrm{~m}$. The hiding time was defined as the period between first adult retreating, to the first adult pika emerging again from burrows [7]. Finally, we measured the vigilance percentage within ten minutes once the pika has left the burrow entrance. The vigilance is the total duration of time that a pika has its head lifted above its back, regardless whether it was quadrupedal or bipedal [68]. 

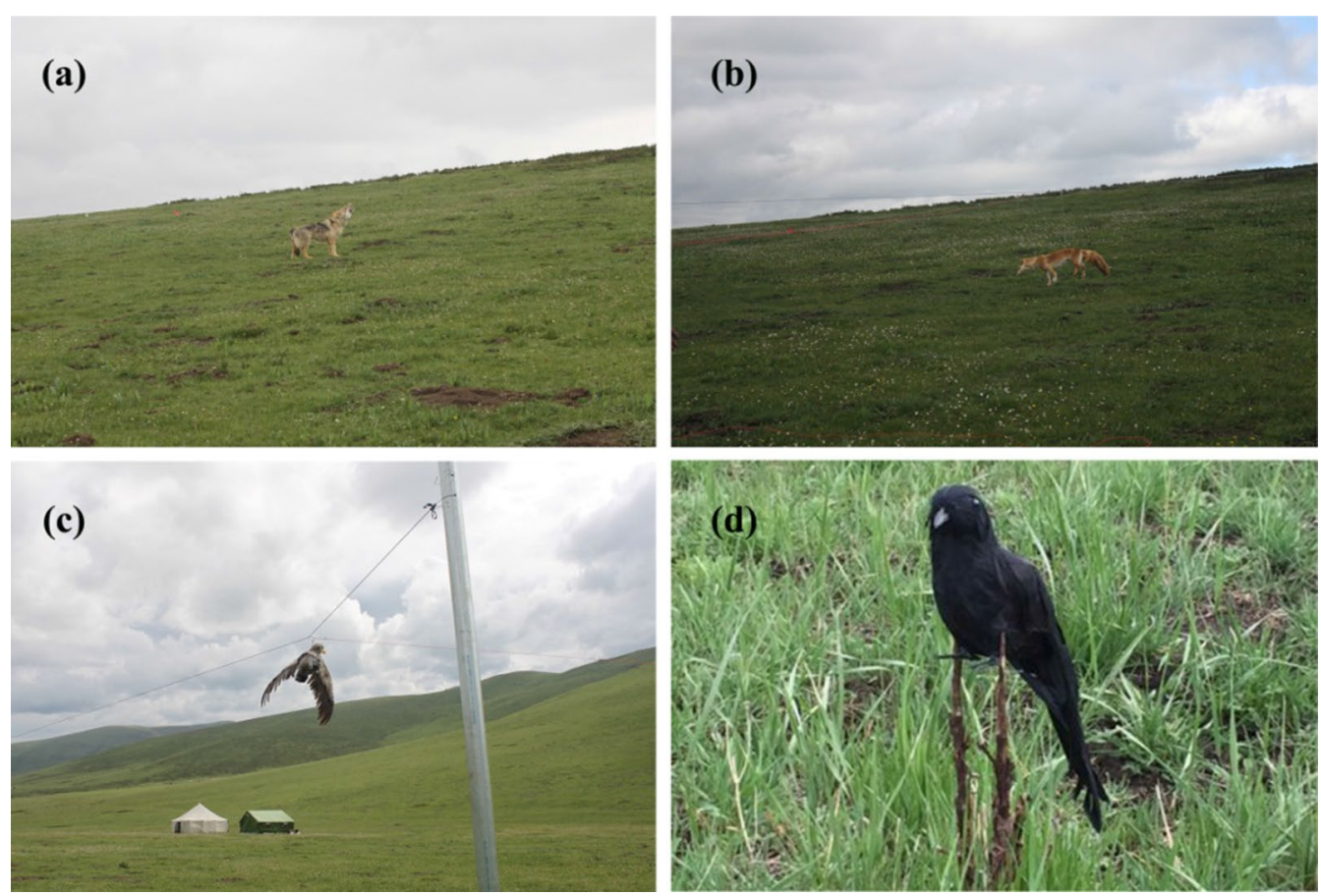

Fig. 4 Four different taxidermy predator species models: a Tibetan fox (Vulpes ferrilata). b Wolf (Canis /upis). c Saker falcon (Falco cherrug). d Large-billed Crow (Corvus macrorhynchos)

\section{Data analyses}

To improve normality, the FID was reciprocally transformed and vigilance was square root transformed, and were tested with general linear models in SPSS 22.0. Pearson correlation coefficients were used to identify collinearity among independent variables. To control for multicollinearity, we tested correlations of pairs of independent variables. Association between variables was assessed using the Spearman correlation index (Rs) and was considered significant when $\mathrm{p}<0.05$. We only maintain one of the correlated collinear variables in the next analysis. The effect of SM on the FID was analyzed using a mixed linear model with GS and RD as covariates, $\mathrm{P}$ and $\mathrm{SD}$ and $\mathrm{EO}$ as random variables and $\mathrm{SM}$ as a fixed variable, $\mathrm{RD}$ and $\mathrm{SD}$ were not included as predictors in the LMMs as GS and RD, SD and EO were highly collinear. Then we fit a model without RD and $\mathrm{SD}$ to test for the main effects. The effect of SM on the vigilance was analyzed using a mixed linear model with GS as covariates, P and SD and EO as random variables and SM as a fixed variable, SD was not included as a predictor in the LMMs as SD and EO were highly collinear. Then we fit a model without SD to test for the main effects. All interactions among these were included in the model and removed if not significant. However, hiding time was not normally distributed despite multiple transformations, therefore we used Nonparametric Tests (Kruskal-Wallis) followed by all pairwise multiple comparisons.

\section{Abbreviations \\ FID: Flight initiation distance; P: Pika populations; SM: Species models; EO: Order; SD: Survey dates; GS: Group size.}

\section{Acknowledgements}

We thank Shenghui An for assistance with the field work.

\section{Authors' contributions}

WRW and QYZ designed the study and analysed the data, WRW, ZMT and QYZ carried out the fieldwork, WRW drafted the manuscript, MKO revised the manuscript, which was commented by all co-authors. All authors gave final approval for publication. All authors read and approved the final manuscript.

\section{Funding}

This research was financially supported by the Special Fund for Agro-Scientific Research in the Public Interest (201203041), the Fundamental Research Funds of China West Normal University (18Q046), and the Gansu Provincial Science and Technology Program (1054nkcp159).

\section{Availability of data and materials}

The datasets used and analysed during the current study are available from the corresponding author on reasonable request.

\section{Ethics approval and consent to participate}

All fieldwork was carried out according to the national legislation. The behavioral studies were in compliance with the legal regulations of China and were approved by the Laboratory Animal Ethics Committee of China West Normal University. 


\section{Consent to publication}

Not applicable.

\section{Competing interests}

The authors declare that they have no competing interests.

\section{Author details}

${ }^{1}$ Key Laboratory of Southwest China Wildlife Resources Conservation, College of life Sciences, China West Normal University, Nanchong 637009, China.

${ }^{2}$ State Key Laboratory of Grassland Agro-Ecosystems, College of Pastoral Agriculture Science and Technology, Lanzhou University, Lanzhou 730200, China. ${ }^{3}$ China West Normal University, Nanchong 637009, China. ${ }^{4}$ Gannan Grassland Workstation in Gansu Province, Hezuo 747000, China. ${ }^{5}$ Department of Zoology and Entomology, University of Pretoria, Private Bag X20, Hatfield 0028, South Africa. ${ }^{6}$ Mammal Research Institute, University of Pretoria, Hatfield 0028 , South Africa.

Received: 25 June 2019 Accepted: 13 July 2020 Published online: 17 July 2020

\section{References}

1. Lundvall D, Svanbäck R, Persson L, Byström P. Size-dependent predation in piscivores: interactions between predator. Can J Fish Aquat Sci. 1999;56(7):1285-92.

2. Magnhagen C, Heibo E. Growth in length and in body depth in young-ofthe-year perch with different predation risk. J Fish Biol. 2004;64(3):612-24.

3. Arnqvist G, Rowe L, Krupa JJ, Sih A. Assortative mating by size: a metaanalysis of mating patterns in water striders. Evol Ecol. 1996;10(3):265-84.

4. Turesson $\mathrm{H}$, Brönmark C. Foraging behaviour and capture success in perch, pikeperch and pike and the effects of prey density. J Fish Biol. 2004;65(2):363-75.

5. Kishida O, Nishimura K. Multiple inducible defences against multiple predators in the anuran tadpole, Rana pirica. Evol Ecol Res. 2005;7(4):619-31.

6. Sih A, Englund G, Wooster D. Emergent impacts of multiple predators on prey. Trends Ecol Evol. 1998;13(9):350-5.

7. Zhang WG, Liu R, Jiang XL. Influence of risk sound signal on behavior pattern of pika. Acta Theriol Sin. 2010;18(1):115-20.

8. Peckarsky BL. Predator-Prey interactions. Behav Process. 2007;18(4):1-16.

9. Dugatkin LA, Godin J-GJ. Prey approaching predators: a cost-benefit perspective. In: Annales Zoologici Fennici. 1992; JSTOR, p:233-252.

10. Dill LM, Fraser $\mathrm{AH}$. The worm re-turns: hiding behavior of a tube-dwelling marine polychaete, Serpula vermicularis. Behav Ecol. 1997;8(2):186-93.

11. Hunter L, Skinner J. Vigilance behaviour in African ungulates: the role of predation pressure. Behaviour. 1998;135(2):195-211.

12. Blumstein DT, Daniel JC, McLean IG. Group size effects in quokkas. Aust J Zool. 2001;49(6):641-9.

13. Sih A, McCarthy TM. Prey responses to pulses of risk and safety: testing the risk allocation hypothesis. Anim Behav. 2002;63(3):437-43.

14. Blumstein DT. Moving to suburbia: ontogenetic and evolutionary consequences of life on predator-free islands. J Biogeogr. 2002;29(6):685-92.

15. Heynen M, Bunnefeld N, Borcherding J. Facing different predators: adaptiveness of behavioral and morphological traits under predation. Curr Zool. 2017;63(3):249-57.

16. Bolt LM, Sauther ML, Cuozzo FP, Jacky IAY. Antipredator vocalization usage in the male ring-tailed lemur (Lemur catta). Folia Primatol. 2015;86(1-2):124-33.

17. Wheeler BC. Selfish or altruistic? An analysis of alarm call function in wild capuchin monkeys, Cebus apella nigritus. Anim Behav. 2008;76(5):1465-75.

18. Bergerud A, Wyett W, Snider B. The role of wolf predation in limiting a moose population. J Wildlife Manage. 1983;47:977-88.

19. Ydenberg RC, Dill LM. The economics of fleeing from predators. Adv Stud Behav. 1986;16:229-49.

20. Formanowicz Jr DR, Brodie Jr ED. Prey density and ambush site changes in Tropisternus lateralis larvae (Coleoptera: Hydrophilidae). J Kans Entomol Soc. 1988:420-427.

21. Cooper WE, Frederick WG. Optimal flight initiation distance. J Theor Biol. 2007;244(1):59-67.
22. Martín J, López P. Hiding time in refuge. Escaping from Predators: An Integrative View of Escape Decisions (WE Cooper, Jr and DT Blumstein, eds) Cambridge University Press, UK. 2015.

23. Stankowich T, Blumstein DT. Fear in animals: a meta-analysis and review of risk assessment. Proc Royal Soc London B Biol Sci. 2005;272(1581):2627-34.

24. McGowan MM, Patel PD, Stroh JD, Blumstein DT. The effect of human presence and human activity on risk assessment and flight initiation distance in skinks. Ethology. 2014;120(11):1081-9.

25. Wei WR. The relationship between population density, vegetation community structure and predation risk of plateau pika. Acta Theriol Sin. 2019;27(2):350-5.

26. LaGory KE. The influence of habitat and group characteristics on the alarm and flight response of white-tailed deer. Anim Behav. 1987;35(1):20-5.

27. Laundré JW, Hernández L, Ripple WJ. The landscape of fear: ecological implications of being afraid[J]. Open Ecol J. 2010;3:1-7.

28. McIntosh AR, Peckarsky BL. Criteria determining behavioural responses to multiple predators by a stream mayfly. Oikos. 1999;85:554-64.

29. Carrascal LM, Moreno E. Proximal costs and benefits of heterospecific social foraging in the Great Tit, Parus major. Can J Zool. 1992;70(10):1947-52.

30. Martín J, Salvador A. Tail loss consequences on habitat use by the Iberian rock lizard, Lacerta monticola. Oikos. 1992;65:328-33.

31. Kavaliers M, Choleris E. Antipredator responses and defensive behavior: ecological and ethological approaches for the neurosciences. Neurosci Biobehav R. 2001;25(7):577-86.

32. Cooper Jr WE, Blumstein DT. Escaping from predators: an integrative view of escape decisions. Cambridge: Cambridge University Press; 2015.

33. Johnson G, Karajah M, Mayo K, Armenta T, Blumstein D. The bigger they are the better they taste: size predicts predation risk and anti-predator behavior in giant clams. J Zool. 2017;301(2):102-7.

34. Krause J, Ruxton GD. Living in groups. Oxford: Oxford University Press; 2002.

35. Eklöv $P$, Werner EE. Multiple predator effects on size-dependent behavior and mortality of two species of anuran larvae. Oikos. 2000;88(2):250-8.

36. Owings DH, Coss RG, McKernon D, Rowe MP, Arrowood PC. Snakedirected antipredator behavior of rock squirrels (Spermophilus variegatus): population differences and snake-species discrimination. Behaviour. 2001;138(5):575-95.

37. Rodriguez-Prieto I, Fernández-Juricic E, Martín J, Regis Y. Antipredator behavior in blackbirds: habituation complements risk allocation. Behav Ecol. 2009;20(2):371-7.

38. Stankowich T, Coss RG. Effects of predator behavior and proximity on risk assessment by Columbian black-tailed deer. Behav Ecol. 2006;17(2):246-54.

39. Stapley J, Keogh JS. Exploratory and antipredator behaviours differ between territorial and nonterritorial male lizards. Anim Behav. 2004;68(4):841-6.

40. Turner JC. Some current issues in research on social identity and self-categorization theories. Soc Identity Context Commit Content. 1999;3(1):6-34.

41. Wei WR, Zhang LF, Yang GR, Xu JW, Fan XD, Zhang WG. A study on the burrow features and functions of plateau pika. Acta Pratacul Sin. 2013;22(6):198-204

42. Schaller GB. Wildlife of the Tibetan steppe. Chicago: University of Chicago Press; 1998.

43. Smith AT, Foggin JM. The plateau pika (Ochotona curzoniae) is a keystone species for biodiversity on the Tibetan plateau. Anim Conserv. 1999;2(4):235-40.

44. Delibes-Mateos M, Smith AT, Slobodchikoff CN, Swenson JE. The paradox of keystone species persecuted as pests: a call for the conservation of abundant small mammals in their native range. Biol Conserv. 2011;144(5):1335-46.

45. Yang SM, Wei WH, Yin BF, Fan NC, Zhou WY. The predation risks of plateau pika and plateau zokor and their survival strategies in apline meadow ecosystem. Acta Ecol Sin. 2007;27(12):4972-8.

46. Ji C, Li J, Yang L. Application of biological control technique of plateau pika in Xi-Zang. XiZang keji. 2010;4(1):65-7.

47. Wei WH, Wang Q, Zhou WY, Fan NC. The population dynamics and dispersal of plateau zokor after removing. Acta Theriol Sin. 1997;17(1):53-61. 
48. Cang JZM, Li JC, Suo LCR, Yang L. The damage of plateau pika to Tibetan grassland and its main natural enemies. XiZang keji. 2010;1:65-7.

49. Helfman $\mathrm{G}$. Threat-sensitive predator avoidance in damselfish-trumpetfish interactions. Behav Ecol Sociobiol. 1989;24(1):47-58.

50. Brodie ED III. Differential avoidance of coral snake banded patterns by free-ranging avian predator in Costa Rica. Evolution. 1993;47(1):227-35.

51. Van HY, Seddon PJ, Maloney RF. Helping reintroduced houbara bustards avoid predation: effective anti-predator training and the predictive value of pre-release behaviour[C]//Animal Conservation forum. Cambridge University Press. 1999;2(3):155-63.

52. Chivers DP, Mirza RS, Bryer PJ, Kiesecker JM. Threat-sensitive predator avoidance by slimy sculpins: understanding the importance of visual versus chemical information. Can J Zool. 2001;79(5):867-73.

53. Tisdale V, Fernández-Juricic E. Vigilance and predator detection vary between avian species with different visual acuity and coverage. Behav Ecol. 2009;20(5):936-45

54. Lima SL, Bednekoff PA. Temporal variation in danger drives antipredator behavior: the predation risk allocation hypothesis. Am Nat. 1999;153(6):649-59.

55. Samia DS, Blumstein DT. Birds flush early and avoid the rush: an interspecific study. PLoS ONE. 2015;10(3):e0119906.

56. Cooper WE. Influence of some potential predation risk factors and interaction between predation risk and cost of fleeing on escape by the lizard Sceloporus virgatus. Ethology. 2011;117(7):620-9.

57. Cooper WE, Blumstein DT. Novel effects of monitoring predators on costs of fleeing and not fleeing explain flushing early in economic escape theory. Behav Ecol. 2014;25(1):44-52

58. Cooper WE, Hawlena D, Pérez-Mellado V. Effects of predation risk factors on escape behavior by Balearic lizards (Podarcis lilfordi) in relation to optimal escape theory. Amphibia-Reptilia. 2009;30(1):99-110.

59. Favreau F-R, Goldizen AW, Pays O. Interactions among social monitoring, anti-predator vigilance and group size in eastern grey kangaroos. Proc Royal Soc London B: Biol Sci. 2010;277:rspb20092337.
60. Lima SL, Dill LM. Behavioral decisions made under the risk of predation: a review and prospectus. Can J Zool. 1990;68(4):619-40.

61. Sih A. Integrative approaches to the study of predation: general thoughts and a case study on sunfish and salamander larvae. In: Annales Zoologici Fennici: 1992; JSTOR: 183-198.

62. Martín J, Lopez P, Cooper WE. When to come out from a refuge: balancing predation risk and foraging opportunities in an alpine lizard. Ethology. 2003;109(1):77-87.

63. Polo-Cavia N, Lopez P, Martin J. Interspecific differences in responses to predation risk may confer competitive advantages to invasive freshwater turtle species. Ethology. 2008;114(2):115-23.

64. Ibáñez A, López P, Martín J. Inter-individual variation in antipredator hiding behavior of spanish terrapins depends on sex, size, and coloration. Ethology. 2014;120(8):742-52.

65. Yin B, Yang S, Shang G, Wei W. Effects of predation risk on behavior, hormone levels, and reproductive success of plateau pikas. Ecosphere. 2017;8(1):e01643

66. Liu M, Qu J, Yang M, Wang Z, Wang Y, Zhang Y, Zhang Z. Effects of quinestrol and levonorgestrel on populations of plateau pikas, Ochotona curzoniae, in the Qinghai-Tibetan Plateau. Pest Manag Sci. 2012;68(4):592-601.

67. Liu W. The survival way of plateau pika. Life World. 2016;3(6):38-41.

68. Smith A, Smith H, Gao XGWX, Xiangchu XY, Junxiun JL. Social behaviour of the steppe-dwelling black-lipped pika. Natl Geogr Res. 1986;2(1):57-74.

\section{Publisher's Note}

Springer Nature remains neutral with regard to jurisdictional claims in published maps and institutional affiliations.
Ready to submit your research? Choose BMC and benefit from:

- fast, convenient online submission

- thorough peer review by experienced researchers in your field

- rapid publication on acceptance

- support for research data, including large and complex data types

- gold Open Access which fosters wider collaboration and increased citations

- maximum visibility for your research: over $100 \mathrm{M}$ website views per year

At BMC, research is always in progress.

Learn more biomedcentral.com/submissions 